\title{
Seed Image Analysis and Its Application in Seed Science Research
}

\author{
Kapadia VN*, Sasidharan N and Kalyanrao Patil \\ Department of Genetics and Plant Breeding, Anand Agricultural University, India
}

Submission: September 26, 2017; Published: November 20, 2017

*Corresponding author: Kapadia VN, Department of Genetics and Plant Breeding, BA College of Agriculture, Agricultural University, Anand-388110, India, Email: Kapadiavn77@gmail.com

\section{Introduction}

The primary criteria for defining the seed quality are purity, germination, moisture and freedom from diseases and insect. The assessment of varietal identity and purity is also contributed by the seed certification procedures. For the proper implementation of PVP and PBR programs in India, DUS characters play a crucial role. Seed image analysis has potential use in determining the cultivar identity of seed lots and testing of the distinctness of new cultivars for the award of breeders' right and cultivar registration. Image-based measurements are fast and easy to achieve the desired objective and thus can provide data correlating with genetic properties of germination and growth performance of seedling.

\section{Advantages of seed image analysis}

a. It is non-invasive and not subjected to any kind of treatment and imaging software provides an increasingly interactive and user-friendly environment to work.

b. Image Analysis has very few additional costs and skilled labour requirement is less and the speed of analysis is much higher than any of the conventional methods.

c. Correct knowledge of the varietal identity of seed /plant part, seed quality is vital to the seed producers, merchant and end users.

d. It can be carried out in less time and the whole process can be automated.

e. It also has the potential to select individual aberrant in large populations allowing upgrading of seed quality.

\section{Case Studies}

\section{Characterization \& identification}

Venora et al. [1] studied to identify of Italian landrace of bean using image analysis system. This study aim to evaluate seed size, shape, colour texture etc., that realized to determine parameters referring to shape and entire seed colour of bean. Method could contribute to the cataloging, conservation and improvement of bean genus and could be used in germplasm bank or ex-situ conservation.

Tanabata et al. [2] used Smart Grain-high throughput phenol typing software measuring seed shape through image analysis in rice. Seed are automatically recognized from digital images and seed parameters such as seed length, width and area. They also used QTL analysis for seed shape of BIL cross between Japonica cultivar Kishihikari and Nippobare, which showed small differences in seed shape.

Yan et al. [3] analyzed purity identification of seeds of four hybrids maize seed based on colour characteristics. The experimental result showed that k-mean algorithm based on one directional space received through fisher discriminant theory, can effectively identify maize seed purity and recognition rate was over 93.75 percent.

\section{Sorting \& grading}

Han et al. [4] studied frequency domain image analysis for detecting stress cracks in corn kernels. A fast fourier transform algorithm was applied to the pre-processed images and the transformation results were condensed into seed feature signatures representing position or orientation invariant morphological features. Stress cracks are internal fissures that can be observed in kernels by x-ray inspection.

Chaugule \& Mali [5] evaluated texture and shape neural network for classification of four paddy varieties. An evaluation of the classification accuracy of texture and shape feature and neural network was done to classify four paddy grains. The most suitable feature from the feature four accurate classifications was identified. The most satisfactory results were delivered by the shape feature set, texture feature set save were accuracy than all the other sets. 


\section{Physiological testing}

Sako et al. [6] studied automated seed vigour assessment in lettuce. Seedling grown for three days in dark the results indicate that the imaging system accurately quantified seed vigour to yield reproducible objective vigour assessment

Silva et al. [7] studied automated system of seedling analysis and electrical conductivity to assess sun hemp seed vigour of SVIS. Evaluations were performed three days after sowing and data on vigour index and length and uniformity of seedling growth were collected. Electrical conductivity measurement at 4 $\mathrm{hr}$ or $8 \mathrm{hr}$ and the use of the SVIS seedling can differently detect difference in vigour between different sun hemp seed lot.

Li et al. [8] studied a self-developed system for visual detection of vegetable seed vigour index. This is done manual \&self-developed SVI system. The results showed higher reorganization accuracy through comparative analysis of four vegetable seeds as well as derivations were 4.32\%, 4.90\%, $5.95 \%$ and $3.22 \%$ respectively and within acceptable limit.

\section{Detection of mechanical, insect \& diseases damage}

Pinto et al. [9] carried an assessment of mechanical and stink bug damage in soybean cultivar BRS-184 by x-ray image analysis technique. Seed from different batches of the BRS184 cultivar were sorted by $\mathrm{x}$-ray test and then were tested for germination. The result showed that the $\mathrm{x}$-ray image analysis technique was effective in detecting mechanical and stink bug damage in soybean seed.

Francisco \& Silvio [10] studied x-ray analysis to assess mechanical damage in sweet corn seeds and its relation to germination and vigour. They calculated x-ray test is efficient in identifying mechanical damage in sweet corn seed, allowing the establishment of a relationship between its occurrence and losses in germination and vigour.

Kinnakari et al. [11] conducted experiment on identification and detection of seed borne diseases of soybean using image processing - a survey. The presence of pathogenic propagules in a seed lot is pivotal because infected seed may fail to germinate, causes infection to seedlings and growing plants. The issues include Identifying and detecting seed-borne diseases of soybean using image processing.

Alencar et al. [12] studied image analysis and physiological quality assessment of seed produce in pumpkin plant infected with the seqush mosaic virus (SqMV). They found that the percentage of abnormal plants and emergence of infected seeds showed significant decrease in the performance, when compared with healthy seeds. The mean of seed emergence and vigour were also lower in the infected seeds.

Vresak et al. [13] studied determination of seed health and variety separation of winter wheat (Triticum aestivum L.) and winter triticale (Tritico secale Wittm. \& Camus).This study produced an interesting result of successful distinguishing between the infected and uninfected parts of the seed surface. Furthermore, the study was able to distinguish between varieties. Together these components could be used in further studies for the development of a sorting model by combining data from multi spectral imaging.

\section{Colour \& surface detection}

Dana et al. [14] used computer image analysis to group together flax cultivars. Based on the results they recommend that current qualitative sensorical seed descriptors routinely used for cultivar characterization may be supplemented by more informative continuous quantitative descriptors obtainable at low cost from dry flax seeds.

Durmas et al. [15] analyzed size prospectus of legumes seeds of different varieties using image analysis from the model data. Estimated specific surface area ranged from (5.1 to 5.8) $\mathrm{cm} 2 / \mathrm{g}$ for bean and (11.57 to 11.55 ) $\mathrm{cm} 2 / \mathrm{g}$ for lentil verities. It provided fast $\&$ accurate value of important technological properties of legumes such as a geometric parameters, volume and surface area.

\section{Conclusion}

a. Considerable work is being done in the field of image processing for different applications of the agriculture and seed industry, particularly more in varietal identification and quality. Eg. beans, paddy, maize and faba bean.

b. Image processing helps to extract low level features such as colour, texture and shape to identify and classify seeds. Eg. flax, bean and lentil.

c. Seed image analysis helps in identification of female parent self and cross seeds of maize.

d. The evaluation of vigour in sun hemp seeds can be made easily and accurately combining both the SVIS and electrical conductivity readings of the seed imbibitions.

e. Seed image analysis study helps in detection of internal seed borne pathogens and insect pest, as well as mechanical damage from intact seeds.

\section{Future Thrust}

a. A major research work is needed in the area of seed image analysis for computing technology along with the sensory and central processing elements.

b. Substantial improvements in this technology is needed so that human error can be minimized

c. There is a need to develop software and hardware which will help in better return on investment and reduced costs.

d. New advances in pattern recognition and massive data processing should be included in future applications of computer vision to enhance the robustness and accuracy of decisions. 
e. In addition, work is also required for online sorting and grading systems to handle large quantities of seeds in seed industries.

\section{References}

1. Venora G, Grillo O, Ravalli C, Cremonini R (2009) Identification of Italian landraces of bean (Phaseolus vulgaris L.) using an image analysis system. Scientia Horticulturae 121(4): 410-418.

2. Tanabata T, Shibaya T, Hori K, Ebana K, Yano M (2012) Smart Grain: High-Throughput Phenotyping Software for Measuring Seed Shape through Image Analysis Plant Physiol 160(4): 1871-1880.

3. Yan X, Wang J, Liu S, Zhang C (2017) Purity identification of maize seed based on color characteristics. $4^{\text {th }}$ Conference on Computer and Computing Technologies in Agriculture (CCTA).

4. Han YJ, Feng,Y, Weller CL (2006) Biological Systems Engineering: Papers and Publications. 12(4):487-492.

5. Chaugule A, Mali SN (2014) Evaluation of texture and shape features for classification of four paddy varieties. Journal of Engineering Article ID 617263: 1-8.

6. Sako Y, McDonald MB, Fujimura K, Evans AF, Bennett MA (2001) A System for Automated Seed Vigor Assessment. The Ohio State University, Columbus, USA.

7. Silva CB, Lopes MM, Filho JM, Vieira RD (2012) Automated system of seedling image analysis (SVIS) and electrical conductivity to assess sun hemp seed vigor. Revista Brasileira de Sementes 34(1): 55-60.
8. Li Z, Wang X, Liao T, Feng Q, Zhang D (2015) International Journal of Agriculture \& Biology, 201x.

9. Pinto TLF, Cicero SM, França NJB, Forti VA (2009) An assessment of mechanical and stink bug damage in soybean seed using X-ray analysis test. Seed Science \& Technololy 37(1): 110-120.

10. Francisco GGJ, Silvio MC (2012) X-Ray analysis to assess mechanical damage in sweet corn seeds. Revista Brasileira de Sementes 34(1): 7885.

11. Kinnikar A, Desai P, Jahagirdar S (2015) Identification and Detection of Seed Borne Diseases of Soybean Using Image Processing -A Survey. International Journal of Emerging Technology in Computer Science \& Electronics 14(2): 363-368.

12. Alencar NE, Figueira AR, Santos HO, Duarte PSG (2016) Image analysis and physiological quality assessment of seeds produced in pumpkin plants infected with the squash mosaic virus (SqMV). Research Journal of Seed Science 9(1): 14-21.

13. Vresak M, Olesen MH, Gislum R, Bavec F, Jorgensen JR (2016) The use of image-spectroscopy technology as a diagnostic method for seed health testing and variety identification. PLoS One 11(3): e0152011.

14. Dana W, Ivo W (2008) Computer image analysis of seed shape and seed color for flax cultivar description. Journal of Food Engineering 61(2): 126-135.

15. Durmus EF, Sarka E, Bubnik Z, Schejbal J, Kadlec P (2010) Size properties of legume seeds of different varieties using image analysis. Journal of Food Engineering 99(4): 445-451.

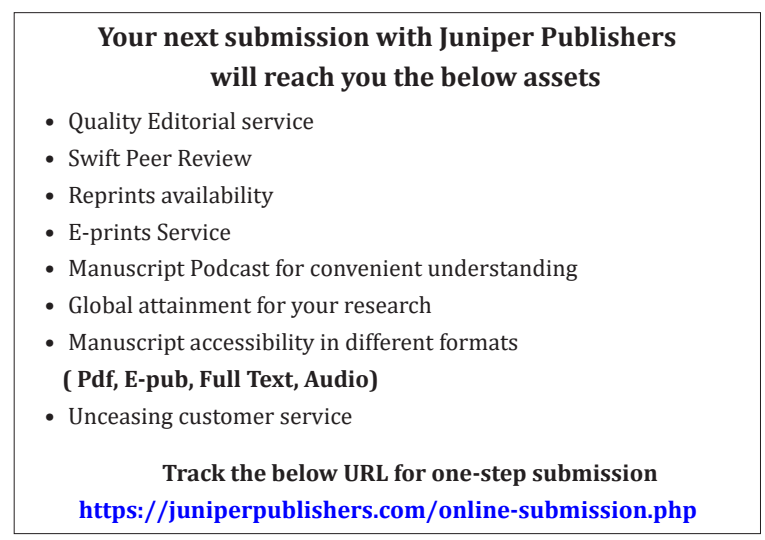

